\title{
Effects of different types of fertilizers application on rice grain quality
}

\author{
Qihua Liu' ${ }^{1}$ Hui Ma', Xiangqing Lin ${ }^{1 *}$, Xuebiao Zhou ${ }^{1}$, and Qinglei Zhao ${ }^{1}$ \\ ${ }^{1}$ Shandong Rice Research Institute, Shandong Academy of Agricultural Sciences, Jinan, 250100, China. \\ "Corresponding author (linxq200803@163.com).
}

Received: 31 August 2018; Accepted: 10 December 2018; doi:10.4067/S0718-58392019000200202

\begin{abstract}
As expected, applications of organic fertilizer and controlled-release fertilizer are gradually varying traditional fertilization, being considered as important channels for substitution of conventional chemical-fertilizer. However, information regarding their effects on rice (Oryza sativa L.) grain quality remains limited. A field experiment was conducted to investigate the effects of combined application of bio-organic fertilizer and conventional fertilizer (BOF+CF), combined application of organic fertilizer and conventional fertilizer (OF+CF), and application of controlled-release fertilizer (CRF) on rice processing quality, eating quality and nutritional quality with conventional fertilizer (CF) and no fertilizer $(\mathrm{NF})$ as controls. The protein content of $\mathrm{OF}+\mathrm{CF}$ treatment was increased by $4.67 \%, 3.29 \%, 2.61 \%$ and $22.66 \%$ when compared to $\mathrm{BOF}+\mathrm{CF}, \mathrm{CRF}, \mathrm{CF}$ and NF. These results imply that, among all treatments, NF produced the highest rice eating quality followed by $\mathrm{CRF}$ and $\mathrm{BOF}+\mathrm{CF}$, and $\mathrm{OF}+\mathrm{CF}$ made the highest nutritional quality followed by $\mathrm{CF}$ and $\mathrm{CRF}$. When compared to $\mathrm{CF}, \mathrm{BOF}+\mathrm{CF}$ and $\mathrm{NF}$ treatments decreased protein content by $1.96 \%$ and $16.34 \%$. Compared to $\mathrm{CF}$, $\mathrm{BOF}+\mathrm{CF}$ treatment markedly reduced aspartic acid, serine, glutamic acid, glycine, alanine, histidine, arginine, and proline contents in milled rice by $17.31,14.71 \%, 16.39 \%, 16.67 \%, 20.69 \%, 11.77 \%, 18.42 \%$, and $18.75 \%$, respectively. The nutritional quality under $\mathrm{NF}$ and $\mathrm{BOF}+\mathrm{CF}$ was significantly decreased when compared with $\mathrm{CF}$, due to the reductions in protein content of milled rice and most amino acids contents of brown and milled rice. These results suggest that a kind of suitable fertilizer could be chosen from them as alternatives according to desired goal in high-quality rice production.
\end{abstract}

Key words: Fertilizer, grain quality, Oryza sativa, rice.

\section{INTRODUCTION}

Chemical fertilizer application plays a vital role in enhancing rice (Oryza sativa L.) grain yield, which has been considered as an effective channel to address the food safety issue due to an increasing population. In recent years, the input of chemical fertilizer is rising rapidly and $\mathrm{N}$ and $\mathrm{P}$ have been overused in rice production, leading to not only environmental pollution but also an increase in production cost (Asman et al., 1998). However, the use efficiency of fertilizer is relatively low in China (Jin, 2012). It was estimated that the recovery efficiencies of N, P and K were only $24.8 \%, 10 \%$, and $25.4 \%$ in rice paddy, respectively (Jin and Yan, 2005). It has been reported that the $\mathrm{N}$ use efficiency in China is only 30\%-35\%, most of which is lost through volatilization, leaching and land surface erosion (Zhu and $\mathrm{Li}, 2003$ ). As a result, a series of problems on lower use efficiencies of fertilizer and pollution because of the excessive application of fertilizer have now posed a challenge for agricultural workers.

Promoting fertilizer use efficiency and reducing its input have an important implication for the boost of economic and ecological benefits (Xing et al., 2015). Focusing on the hot issue, a numerous researches about the effects of controlledrelease fertilizer and the combined application of inorganic and organic fertilizers on physicochemical traits of soil and grain yield in rice have been conducted (Li et al., 2013; Peng et al., 2013; Miao et al., 2016; Huang et al., 2017; 
Moe et al., 2017). Wang et al. (2012) found that a 4-yr application of pig-manure compost to crop fields demonstrated an enhancement in organic-C and $\mathrm{N}$ concentrations in soil. Moe et al. (2017) reported that the combined application of inorganic fertilizer and organic manures was instrumental in decreasing the use of chemical fertilizer and improving $\mathrm{N}$ uptake in rice, resulting in better environment. Xing et al. (2015) and Miao et al. (2016) observed that an application of controlled-release fertilizer accompanied by tiller urea could increase the creation of photosynthetic matter, $\mathrm{N}$ use efficiency and grain yield in rice. All these literatures suggest that optimizing $\mathrm{N}$ fertilization application strategy through the use of chemical fertilizer in conjunction with organic fertilizer and controlled-release fertilizer appears to be feasible for reducing chemical fertilizer application rate and improving soil fertility and rice grain yield. Nevertheless, information regarding the effect of combined application of chemical fertilizer with organic fertilizer and the effect of controlledrelease fertilizer on rice grain quality is still limited now.

With the increment of consumption level in China, the consumer's requirement for rice grain quality is becoming more and more rigid. Much attention has been paid to enhancing grain quality in rice production (Cai et al., 2011; Liu et al., 2014; 2015). In general, rice grain quality was determined by many factors, such as cultivation condition, fertilizer application method and water management (Lu et al., 2007; Zhang et al., 2008; Liu et al., 2014). It has been established that fertilizer application is a key factor responsible for rice grain quality (Dou et al., 2017). The aim of the study was to assess the effects of different types of fertilizers treatments on rice grain quality.

\section{MATERIALS AND METHODS}

\section{Site and soil fertility description}

The present experiment was conducted in Gudao Town ( $37^{\circ} 47^{\prime}$ N, $118^{\circ} 39$ E; 5 m a.s.l.), Dongying County, Shandong Province, China. The basic fertility of the soil in the experimental site was as follows: $\mathrm{pH} 7.12$, organic matter $6.82 \mathrm{~g} \mathrm{~kg}^{-1}$, total $\mathrm{N} 1.00 \mathrm{~g} \mathrm{~kg}^{-1}$, available $\mathrm{N} 26.93 \mathrm{mg} \mathrm{kg}^{-1}$, available $\mathrm{P} 12.06 \mathrm{mg} \mathrm{kg}^{-1}$, and available $\mathrm{K} 92.73 \mathrm{mg} \mathrm{kg}^{-1}$.

\section{Experiment design and cultivation management}

The experiment was arranged as a randomized complete block design with three replicates. There were five treatments in the experiment, including the combined application of bio-organic fertilizer and conventional fertilizer (BOF+CF), combined application of organic fertilizer and conventional fertilizer ( $\mathrm{OF}+\mathrm{CF})$, single application of controlled-release fertilizer (CRF), application of conventional fertilizer (CF) and no fertilizer application (NF). The conventional fertilizer application method was depicted as follows: diammonium phosphate $(18 \% \mathrm{~N}$ and $46 \%$ phosphorus pentoxide) was applied as basal fertilizer at a rate of $300 \mathrm{~kg} \mathrm{ha}^{-1}$. Additionally, urea $(46 \% \mathrm{~N})$ was top-dressed at a rate $262.5 \mathrm{~kg} \mathrm{ha}^{-1}$ at seedling establishment, 225 $\mathrm{kg} \mathrm{ha}^{-1}$ at tillering stage and $112.5 \mathrm{~kg} \mathrm{ha}^{-1}$ at panicle initiation stage, respectively. The bio-organic fertilizer ( $\geq 200$ million bifidobacteria per gram, organic matter content $\geq 40 \%$ ) and organic fertilizer (organic matter content $\geq 45 \%$ ) were all applied as basal fertilizer at a rate of $2400 \mathrm{~kg} \mathrm{ha}^{-1}$. The controlled-release fertilizer ( $\left.25 \% \mathrm{~N}-15 \% \mathrm{P}-6 \% \mathrm{~K}\right)$ was applied once as basal fertilizer at a rate of $1050 \mathrm{~kg} \mathrm{ha}^{-1}$. To avoid the movement of water and fertilizer, five treatments were separated by ridges. These ridges were covered by plastic film which was inserted into the soil at $30 \mathrm{~cm}$ depth.

A japonica rice (Oryza sativa L.) cultivar (Shengdao 19), which has been widely cultivated in local production, was used in the field experiment. Dry rice seeds were sown in line in May with sowing rate $150 \mathrm{~kg} \mathrm{ha}^{-1}$. The row distance was $20 \mathrm{~cm}$ and sowing depth was $1 \mathrm{~cm}$. Other cultivation management was carried out according to local practices.

\section{Measurements}

At maturity, rice plants were harvested. When moisture content reached $14 \%$, rice grains were stored under dry condition before quality measurement. Brown rice yield and milled rice yield were assayed by the method from rice measurement standards (NY147-88; Ministry of Agriculture, PR China, 1988). Briefly, a total $130 \mathrm{~g}$ sample of rice grains were passed through a rice mill grain analytical machine (JGMJ8098, Shanghai JD Grain and Oil Instrument Ltd., Shanghai, China) measuring brown and milled rice to be dehulled, then brown rice was weighed. After that, brown rice was passed through the machine again to remove pericarp layer and obtain milled rice, subsequently milled rice was also weighed. The brown rice yield and milled rice yield were defined as mass fractions of the total grain weight. Taste score for milled rice was measured by a machine evaluating rice eating quality (JSWL200, SATAKE, Beijing Dongfu Jiuheng Instrument Technology Ltd. 
and kabuskiki kaisha). Amylose content in milled rice was assayed according to the Chinese standard NY147-88. The starch viscosity of milled rice was measured with a Rapid Visco Analyser (RVA; Starchmaster 2, Perten Instruments of Australia Pty Ltd., Sydney, New South Wales, Australia) according to American Association of Cereal Chemists (AACC) International Approved Method 61-02.01. Viscous profile characteristics were evaluated by a RVA and expressed as peak viscosity, trough viscosity, final viscosity, breakdown (difference between peak viscosity and trough viscosity), and setback (difference between final viscosity and peak viscosity). Protein content of milled rice was assayed with a nitrogen analyzer (AutoKjeldahl Unit K-370, Büchi Labortechnik, Flawil, Switzerland) by AACC International Approved Method 46-30.01. The conversion coefficient between $\mathrm{N}$ and protein content is 5.95. Amino acids content in brown rice and milled rice was measured by a full-automatic amino acids analyzer (L-8800, Hitachi Limited Corporation, Tokyo, Japan) according to the national standard of the People's Republic of China (Ministry of Agriculture PR China, 1988).

\section{Statistical analysis}

Multiple comparisons between treatments were performed by SPSS 16.0 statistical programs package (IBM, Armonk, New York, USA). The means of every treatments were compared with the least significant difference (LSD) test at the $\mathrm{p}<0.05$ probability level. Figures were produced by SigmaPlot 10.0 programs package (Systat Software Inc., San Jose, California, USA).

\section{RESULTS AND DISCUSSION}

\section{Effect of combined application on rice grain quality}

There were nonsignificant differences in brown rice yield and milled rice yield between BOF+CF and CF (Figure 1). Similar results were observed between the $\mathrm{OF}+\mathrm{CF}$ and $\mathrm{CF}$. The brown rice yield under $\mathrm{BOF}+\mathrm{CF}$ and $\mathrm{OF}+\mathrm{CF}$ treatments markedly increased by $4.11 \%$ and $4.19 \%$ as compared to that under NF treatment. Similar results were found in milled rice yield and the corresponding values were $6.01 \%$ and $6.51 \%$, respectively.

In general, amylose content is deemed as an index evaluating rice eating quality. In some cases, amylose content of milled rice is negatively related with rice eating quality. In the current study, when compared with $\mathrm{CF}, \mathrm{BOF}+\mathrm{CF}$ and $\mathrm{OF}+\mathrm{CF}$ did not show pronounced influences on amylose content of milled rice (Figure 2). The amylose content of milled rice under $\mathrm{OF}+\mathrm{CF}$ treatment significantly reduced by $2.68 \%$ when compared to NF. There was nonsignificant difference in amylose content of milled rice between $\mathrm{BOF}+\mathrm{CF}$ and NF. Taste score for milled rice is a key index determining rice eating quality. Rice with good eating quality usually has high taste score and vice versa. The taste score of milled rice was significantly enhanced from 74.5 under $\mathrm{CF}$ to 76.0 under $\mathrm{BOF}+\mathrm{CF}$ (Figure 3). The difference in taste score of milled rice between $\mathrm{OF}+\mathrm{CF}$ and $\mathrm{CF}$ was not marked. However, the taste scores of milled rice under $\mathrm{BOF}+\mathrm{CF}$ and $\mathrm{OF}+\mathrm{CF}$ were all significantly lower than that under NF. The RVA profile characteristics have been identified as important parameters evaluating starch paste properties, therefore determining rice eating quality. Peak viscosity and breakdown have been confirmed to be positively and significantly correlated with rice eating quality while setback has opposite performance (Toyoshima et al., 1997). In the present investigation, peak viscosity and breakdown under BOF+CF were $7.16 \%$ and $8.54 \%$ higher than those under $\mathrm{CF}$ (Table 1). Conversely, the setback under BOF+CF was $19.56 \%$ lower than that under $\mathrm{CF}$. All these differences were significant. Compared to $\mathrm{CF}, \mathrm{OF}+\mathrm{CF}$ did not exhibit noticeable influence on breakdown and setback. BOF $+\mathrm{CF}$ and $\mathrm{OF}+\mathrm{CF}$ treatments significantly reduced peak viscosity and breakdown but increased setback, as compared with NF.

Protein and amino-acids contents have been recognized as important parameters reflecting rice nutritional quality. A pronounced decline in protein content of milled rice was observed under $\mathrm{BOF}+\mathrm{CF}$ whereas it showed a significant increment under $\mathrm{OF}+\mathrm{CF}$, compared with $\mathrm{CF}$ (Figure 4). The protein content under $\mathrm{BOF}+\mathrm{CF}$ and $\mathrm{OF}+\mathrm{CF}$ treatments was markedly higher than that under NF. In terms of essential amino-acids contents in milled rice, $\mathrm{OF}+\mathrm{CF}$ treatment noticeably enhanced valine (Val), leucine (Leu) and phenylalanine (Phe) contents while BOF+CF treatment significantly reduced threonine (Thr), Val, isoleucine (Ile), Leu, Phe and lysine (Lys) contents, as compared to CF (Table 2). As for essential amino-acids contents in brown rice, $\mathrm{OF}+\mathrm{CF}$ treatment pronouncedly increased Val, methionine (Met), Ile, Leu and Phe contents whereas $\mathrm{BOF}+\mathrm{CF}$ treatment markedly decreased Val, Met, Leu contents, as compared with CF. All essential 
Figure 1. Effects of combined application of different types of fertilizers on brown rice yield and milled rice yield.
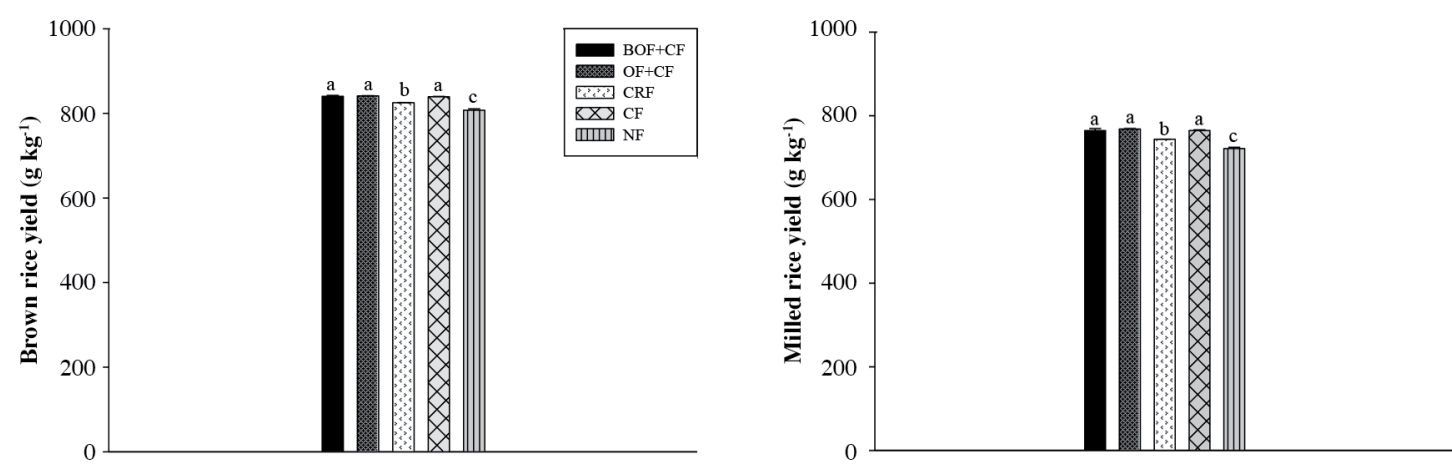

$\mathrm{BOF}+\mathrm{CF}$ : Bio-organic fertilizer plus conventional fertilizer; $\mathrm{OF}+\mathrm{CF}$ : organic fertilizer plus conventional fertilizer; CRF: controlled-release fertilizer; $\mathrm{CF}$ : conventional fertilizer; NF: no fertilizer.

Different letters between treatments indicate a significant difference at $\mathrm{p}<0.05$.

Figure 2. Effects of combined application of different types of fertilizers on amylose content in milled rice.

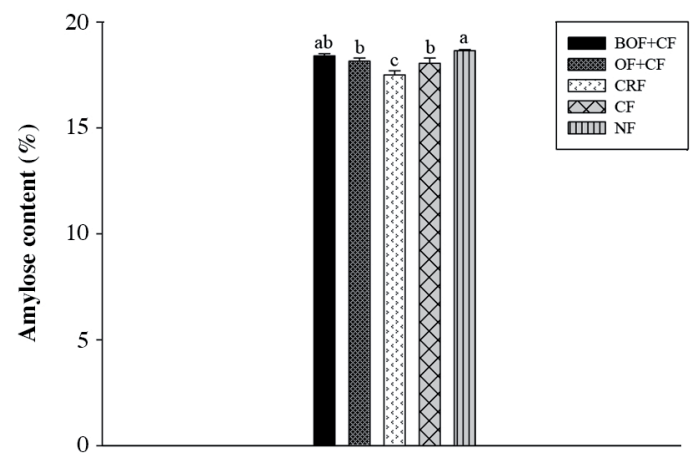

$\mathrm{BOF}+\mathrm{CF}$ : Bio-organic fertilizer plus conventional fertilizer; $\mathrm{OF}+\mathrm{CF}$ : organic fertilizer plus conventional fertilizer; CRF: controlled-release fertilizer; CF: conventional fertilizer; NF: no fertilizer.

Different letters between treatments indicate a significant difference at $\mathrm{p}<0.05$.

amino-acids in brown and milled rice (except for Met content of milled rice) were significantly lower under NF treatment than those under $\mathrm{OF}+\mathrm{CF}$ and $\mathrm{CF}$ treatments. Compared to $\mathrm{CF}, \mathrm{BOF}+\mathrm{CF}$ treatment markedly reduced aspartic acid (Asp), serine (Ser), glutamic acid (Glu), glycine (Gly), alanine (Ala), histidine (His), arginine (Arg), and proline (Pro) contents in milled rice as well as Asp, cysteine (Cys), Thr and Arg contents in brown rice. On the contrary, when compared to $\mathrm{CF}, \mathrm{OF}+\mathrm{CF}$ treatment pronouncedly enhanced Asp and Glu contents in milled rice. Likewise, significant increments in Asp, Ser, Glu, Gly, Ala contents of brown rice were also observed under $\mathrm{OF}+\mathrm{CF}$ treatment. However, $\mathrm{OF}+\mathrm{CF}$ treatment significantly reduced Thr and Pro contents in brown rice as compared to CF. Most non-essential amino-acids contents in milled and brown rice (excluding Cys and Thr contents of milled rice) under NF were noticeably lower than those under $\mathrm{OF}+\mathrm{CF}$ and $\mathrm{CF}$ treatments.

Previous research indicated that the combined application of organic and inorganic fertilizers could promote nutrient synchrony and use efficiency of $\mathrm{N}$ and lower nutrient losses by converting inorganic $\mathrm{N}$ into organic forms (Kramer et al., 2002). Meng et al. (2009) reported that substitution of 10\%-20\% inorganic $\mathrm{N}$ with organic $\mathrm{N}$ evidently enhanced $\mathrm{N}$ utilization efficiency and grain yield in rice. Tang et al. (2015) found that the application of $50 \%$ chemical fertilizer in conjunction with 50\% organic fertilizer was capable of increasing the weight of the grain located in the upper and middle parts of a panicle and the seed-setting rate of the secondary branches in the middle and bottom parts of a panicle. In addition, the significant increment in rice grain yield due to the application of bio-organic fertilizer was reported 
Figure 3. Effects of combined application of different types of fertilizers on taste score for milled rice.

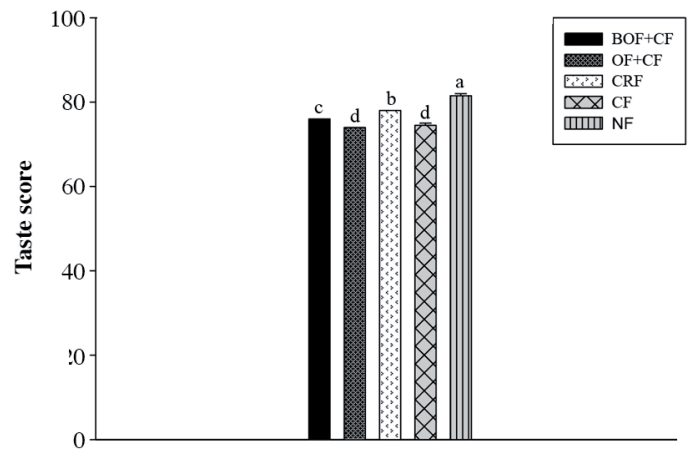

$\mathrm{BOF}+\mathrm{CF}$ : Bio-organic fertilizer plus conventional fertilizer; $\mathrm{OF}+\mathrm{CF}$ : organic fertilizer plus conventional fertilizer; CRF: controlled-release fertilizer; $\mathrm{CF}$ : conventional fertilizer; NF: no fertilizer.

Different letters between treatments indicate a significant difference at $p<0.05$

Table 1. Effects of combined application of different types of fertilizers on viscous profile characteristics of milled rice.

\begin{tabular}{lccccr}
\hline Treatment & Peak viscosity & Trough viscosity & Final viscosity & Breakdown & Setback \\
\hline & & & RVU & & \\
BOF+CF & $149.58 \mathrm{c}$ & $82.33 \mathrm{c}$ & $168.63 \mathrm{~b}$ & $67.25 \mathrm{~b}$ & $19.04 \mathrm{~b}$ \\
OF+CF & $143.63 \mathrm{~d}$ & $80.13 \mathrm{~cd}$ & $166.58 \mathrm{bc}$ & $63.50 \mathrm{c}$ & $22.96 \mathrm{a}$ \\
$\mathrm{CRF}$ & $153.00 \mathrm{~b}$ & $85.75 \mathrm{~b}$ & $172.08 \mathrm{~b}$ & $67.25 \mathrm{~b}$ & $19.08 \mathrm{~b}$ \\
$\mathrm{CF}$ & $139.58 \mathrm{e}$ & $77.63 \mathrm{~d}$ & $163.25 \mathrm{c}$ & $61.96 \mathrm{c}$ & $23.67 \mathrm{a}$ \\
$\mathrm{NF}$ & $182.63 \mathrm{a}$ & $97.38 \mathrm{a}$ & $189.58 \mathrm{a}$ & $85.25 \mathrm{a}$ & $6.96 \mathrm{c}$ \\
\hline
\end{tabular}

$\mathrm{BOF}+\mathrm{CF}$ : Bio-organic fertilizer plus conventional fertilizer; $\mathrm{OF}+\mathrm{CF}$ : organic fertilizer plus conventional fertilizer; CRF: controlled-release fertilizer; $\mathrm{CF}$ : conventional fertilizer; NF: no fertilizer; RVU: rapid visco units.

Values followed by different letters represent significant difference at $\mathrm{p}<0.05$.

by Zhang et al. (2014). All these literatures suggest the positive effects of organic and bio-organic fertilizers on rice production. In the current study, we found that, compared to $\mathrm{CF}, \mathrm{BOF}+\mathrm{CF}$ dramatically enhanced rice eating quality and $\mathrm{OF}+\mathrm{CF}$ markedly increased rice nutritional quality (especially brown rice nutrition quality). The result was primarily in accordance with that reported by Wang et al. (2004), who observed an improvement in rice eating and nutritional qualities because of the combined application of organic and chemical fertilizers under rice-duck mutualism condition. Interestingly, we observed that $\mathrm{BOF}+\mathrm{CF}$ generated more influences on amino-acids contents in milled rice than those in brown rice, conversely, $\mathrm{OF}+\mathrm{CF}$ showed more influences on amino-acids in brown rice than

Figure 4. Effects of combined application of different types of fertilizers on protein content in milled rice.

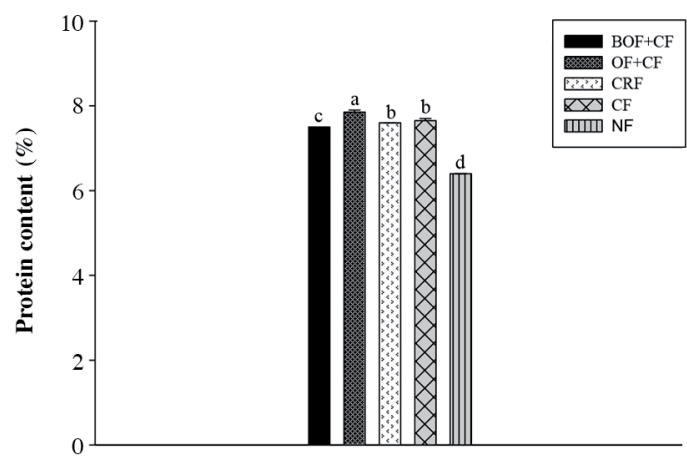

BOF+CF: Bio-organic fertilizer plus conventional fertilizer; $\mathrm{OF}+\mathrm{CF}$ : organic fertilizer plus conventional fertilizer;

CRF: controlled-release fertilizer; $\mathrm{CF}$ : conventional fertilizer; NF: no fertilizer.

Different letters between treatments indicate a significant difference at $\mathrm{p}<0.05$. 
Table 2. Effects of combined application of different types of fertilizers on essential amino-acids contents in milled rice and brown rice.

\begin{tabular}{lcccccccc}
\hline Treatment & & Thr & Val & Met & Ile & Leu & Phe & Lys \\
\cline { 3 - 8 } Milled rice & BOF+CF & $0.19 \mathrm{~b}$ & $0.27 \mathrm{c}$ & $0.01 \mathrm{a}$ & $0.17 \mathrm{~b}$ & $0.43 \mathrm{c}$ & $0.26 \mathrm{c}$ & $0.16 \mathrm{c}$ \\
& OF+CF & $0.23 \mathrm{a}$ & $0.35 \mathrm{a}$ & $0.01 \mathrm{a}$ & $0.22 \mathrm{a}$ & $0.51 \mathrm{a}$ & $0.32 \mathrm{a}$ & $0.21 \mathrm{a}$ \\
& CRF & $0.22 \mathrm{a}$ & $0.33 \mathrm{~b}$ & $0.01 \mathrm{a}$ & $0.21 \mathrm{a}$ & $0.49 \mathrm{~b}$ & $0.31 \mathrm{~b}$ & $0.19 \mathrm{a}$ \\
& $\mathrm{CF}$ & $0.22 \mathrm{a}$ & $0.33 \mathrm{~b}$ & $0.01 \mathrm{a}$ & $0.21 \mathrm{a}$ & $0.49 \mathrm{~b}$ & $0.30 \mathrm{~b}$ & $0.20 \mathrm{a}$ \\
& NF & $0.17 \mathrm{c}$ & $0.25 \mathrm{~d}$ & $0.02 \mathrm{a}$ & $0.15 \mathrm{c}$ & $0.37 \mathrm{~d}$ & $0.23 \mathrm{~d}$ & $0.15 \mathrm{c}$ \\
\hline Brown rice & BOF+CF & $0.24 \mathrm{~b}$ & $0.34 \mathrm{c}$ & $0.02 \mathrm{c}$ & $0.22 \mathrm{~b}$ & $0.50 \mathrm{~d}$ & $0.31 \mathrm{~b}$ & $0.23 \mathrm{a}$ \\
& OF+CF & $0.28 \mathrm{a}$ & $0.40 \mathrm{a}$ & $0.07 \mathrm{a}$ & $0.25 \mathrm{a}$ & $0.58 \mathrm{a}$ & $0.37 \mathrm{a}$ & $0.22 \mathrm{a}$ \\
& CRF & $0.25 \mathrm{~b}$ & $0.36 \mathrm{~b}$ & $0.01 \mathrm{c}$ & $0.23 \mathrm{~b}$ & $0.54 \mathrm{~b}$ & $0.32 \mathrm{~b}$ & $0.24 \mathrm{a}$ \\
& CF & $0.26 \mathrm{ab}$ & $0.36 \mathrm{~b}$ & $0.04 \mathrm{~b}$ & $0.23 \mathrm{~b}$ & $0.52 \mathrm{c}$ & $0.33 \mathrm{~b}$ & $0.24 \mathrm{a}$ \\
\hline
\end{tabular}

$\mathrm{BOF}+\mathrm{CF}$ : Bio-organic fertilizer plus conventional fertilizer; $\mathrm{OF}+\mathrm{CF}$ : organic fertilizer plus conventional fertilizer; CRF: controlled-release fertilizer; $\mathrm{CF}$ : conventional fertilizer; NF: no fertilizer; Thr: threonine; Val: valine; Met: methionine; Ile: isoleucine; Leu: leucine; Phe: phenylalanine; Lys: lysine.

Values followed by different letters represent significant difference at $\mathrm{p}<0.05$.

those in milled rice. Rice eating quality under NF treatment was significantly higher than that under BOF+CF and $\mathrm{OF}+\mathrm{CF}$ treatments, which was closely linked to the marked reduction in protein content of milled rice under NF. That is because protein could influence starch gelatinization through the agency of a network linked by disulfide bonds, thereby leading to poor rice eating quality (Martin and Fitzgerald, 2002).

\section{Effect of controlled-release fertilizer on rice grain quality}

The brown rice yield and milled rice yield under CRF treatment pronouncedly declined by $1.69 \%$ and $2.71 \%$, respectively, as compared to $\mathrm{CF}$, however, they significantly increased by $2.21 \%$ and $3.12 \%$, respectively, when compared to NF (Figure 1).

The amylose content of milled rice under CRF fertilizer was 3.05\% and 6.17\% lower than that under CF and NF treatments (Figure 2). The taste score for milled rice under CRF treatment was significantly higher than that under CF but lower than that under NF (Figure 3). CRF treatment dramatically enhanced peak viscosity and breakdown by $9.62 \%$ and $8.53 \%$ while it decreased setback by $19.39 \%$, as compared with CF (Table 1). When compared to NF, peak viscosity and breakdown was noticeably reduced by $16.22 \%$ and $21.11 \%$ but setback was increased by $174.14 \%$ under CRF.

A nonsignificant difference in protein content between CRF treatment and CF treatment was observed (Figure 4). In contrast with NF, the protein content of milled rice under CRF was significantly increased by $18.75 \%$. There were nonsignificant difference in essential amino-acids contents of milled rice between CRF treatment and CF treatment (Table 2). Compared to $\mathrm{CF}$, the Met content of brown rice was markedly reduced while Leu content of brown rice was pronouncedly increased under CRF. Most essential amino-acids contents under CRF treatment were significantly higher than those under NF (except Met content of milled and brown rice). Insignificant differences in non-essential amino-acids contents of milled rice between CRF treatment and CF treatment were observed (Table 3). When compared to CF, the Glu, Ala, Cys, Thr and Arg contents of brown rice under CRF dramatically declined. All non-essential amino-acids contents of milled rice and brown rice under NF were significantly lower than those under CRF.

It has been established that controlled-release fertilizer is characterized by a slow nutrient release speed and a long release period, meeting the nutrient requirement for crop during the whole growth stage (Halvorson et al., 2010; Wilson et al., 2010). The nutrient release of controlled-release fertilizer and the nutrient absorption of crop occur simultaneously, which obviously reduces fertilizer application times and promotes the use efficiency of fertilizer (Guetral, 2000; Shoji et al., 2001). Focusing on the application effect of controlled-release fertilizer, considerable researches have been carried out under field condition (Huang et al., 2006; Xing et al., 2015). Peng et al. (2013) reported that the application of controlledrelease fertilizer could promote rice root growth and root distribution in deep soil and maintain root vigor. Huang et al. (2006) reported that one-time application of controlled-release fertilizer prominently enhanced rice grain yield. Miao et al. (2016) found that slow-release fertilizer blend was capable of meeting rice $\mathrm{N}$ demand and improving $\mathrm{N}$ use efficiency 
Table 3. Effects of combined application of different types of fertilizers on non-essential amino-acids contents in milled rice and brown rice.

\begin{tabular}{|c|c|c|c|c|c|c|c|c|c|c|c|}
\hline \multicolumn{2}{|c|}{ Treatment } & Asp & Ser & Glu & Gly & Ala & Cys & Thr & His & Arg & Pro \\
\hline \multirow[t]{5}{*}{ Milled rice } & $\mathrm{BOF}+\mathrm{CF}$ & $0.43 c$ & $0.29 b$ & $1.02 \mathrm{c}$ & $0.20 b$ & $0.23 \mathrm{~b}$ & $0.09 \mathrm{a}$ & $0.06 \mathrm{a}$ & $0.15 b$ & $0.31 \mathrm{c}$ & $0.26 \mathrm{~b}$ \\
\hline & $\mathrm{OF}+\mathrm{CF}$ & $0.55 \mathrm{a}$ & $0.34 \mathrm{a}$ & $1.24 \mathrm{a}$ & $0.25 \mathrm{a}$ & $0.29 \mathrm{a}$ & $0.08 \mathrm{a}$ & $0.07 \mathrm{a}$ & $0.17 \mathrm{a}$ & $0.41 \mathrm{a}$ & $0.32 \mathrm{a}$ \\
\hline & CRF & $0.52 b$ & $0.34 \mathrm{a}$ & $1.22 \mathrm{~b}$ & $0.24 \mathrm{a}$ & $0.28 \mathrm{a}$ & $0.09 \mathrm{a}$ & $0.08 \mathrm{a}$ & $0.16 \mathrm{ab}$ & $0.37 \mathrm{~b}$ & $0.32 \mathrm{a}$ \\
\hline & $\mathrm{CF}$ & $0.52 b$ & $0.34 \mathrm{a}$ & $1.22 \mathrm{~b}$ & $0.24 \mathrm{a}$ & $0.29 a$ & $0.09 \mathrm{a}$ & $0.07 \mathrm{a}$ & $0.17 \mathrm{a}$ & $0.38 b$ & $0.32 \mathrm{a}$ \\
\hline & NF & $0.39 \mathrm{~d}$ & $0.25 \mathrm{c}$ & $0.88 \mathrm{~d}$ & $0.19 b$ & $0.22 b$ & $0.09 \mathrm{a}$ & $0.08 \mathrm{a}$ & $0.11 \mathrm{c}$ & $0.27 \mathrm{~d}$ & $0.20 \mathrm{c}$ \\
\hline \multirow[t]{5}{*}{ Brown rice } & $\mathrm{BOF}+\mathrm{CF}$ & $0.56 \mathrm{c}$ & $0.35 b$ & $1.24 \mathrm{c}$ & $0.27 b$ & $0.31 \mathrm{c}$ & $0.09 \mathrm{~b}$ & $0.09 \mathrm{c}$ & $0.19 \mathrm{a}$ & $0.40 \mathrm{~d}$ & $0.34 \mathrm{a}$ \\
\hline & $\mathrm{OF}+\mathrm{CF}$ & $0.66 \mathrm{a}$ & $0.41 \mathrm{a}$ & $1.43 \mathrm{a}$ & $0.30 \mathrm{a}$ & $0.35 \mathrm{a}$ & $0.12 \mathrm{a}$ & $0.12 \mathrm{~b}$ & $0.19 \mathrm{a}$ & $0.52 \mathrm{a}$ & $0.30 \mathrm{~b}$ \\
\hline & CRF & $0.60 \mathrm{~b}$ & $0.36 \mathrm{~b}$ & $1.29 \mathrm{~b}$ & $0.28 b$ & $0.33 b$ & $0.08 \mathrm{~b}$ & $0.11 \mathrm{~b}$ & $0.18 \mathrm{a}$ & $0.43 c$ & $0.35 \mathrm{a}$ \\
\hline & $\mathrm{CF}$ & $0.60 \mathrm{~b}$ & $0.36 \mathrm{~b}$ & $1.25 \mathrm{c}$ & $0.27 \mathrm{~b}$ & $0.29 \mathrm{c}$ & $0.11 \mathrm{a}$ & $0.16 \mathrm{a}$ & $0.19 \mathrm{a}$ & $0.49 \mathrm{~b}$ & $0.34 \mathrm{a}$ \\
\hline & NF & $0.37 \mathrm{~d}$ & $0.23 c$ & $0.82 d$ & $0.19 \mathrm{c}$ & $0.21 d$ & $0.06 \mathrm{c}$ & $0.08 \mathrm{c}$ & $0.15 b$ & $0.26 \mathrm{e}$ & $0.24 \mathrm{c}$ \\
\hline
\end{tabular}

BOF+CF: Bio-organic fertilizer plus conventional fertilizer; $\mathrm{OF}+\mathrm{CF}$ : organic fertilizer plus conventional fertilizer; $\mathrm{CRF}$ : controlled-release fertilizer; CF: conventional fertilizer; NF: no fertilizer; Asp: aspartic acid; Ser: serine; Glu: glutamic acid; Gly: glycine; Ala: alanine; Cys: cysteine; Thr: threonine; His: histidine; Arg: arginine; Pro: proline.

Values followed by different letters represent significant difference at $\mathrm{p}<0.05$.

and grain yield. In the current study, we observed that, compared to conventional fertilizer, the application of controlledrelease fertilizer significantly increased rice eating quality while was unfavorable to the enhancement of brown and milled rice yield.

\section{CONCLUSIONS}

Rice eating quality under no fertilizer application (NF) was better than under combined application of organic fertilizer and conventional fertilizer $(\mathrm{OF}+\mathrm{CF})$, combined application of bio-organic fertilizer and conventional fertilizer (BOF+CF), controlled-release fertilizer (CRF) and conventional fertilizer $(\mathrm{CF})$, but rice processing and nutrition qualities under $\mathrm{NF}$ were poorer than those under other treatments. In contrast with $\mathrm{CF}, \mathrm{BOF}+\mathrm{CF}$ treatment evidently enhanced rice eating quality but reduced nutritional quality. The $\mathrm{OF}+\mathrm{CF}$ treatment markedly increased rice nutritional quality and did not show significant influence on rice eating quality as compared to CF. The CRF treatment also evidently improved rice eating quality while it decreased brown rice yield and milled rice yield when compared with CF.

\section{ACKNOWLEDGEMENTS}

The research was financially supported by Agricultural scientific and technical innovation project of Shandong Academy of Agricultural Sciences (CXGC2018B04), Shandong key research and development project (2016CYJS05A01-6), Shandong Modern Agricultural Technology \& Industry System (SDAIT-17-01) and the earmarked fund for China Agriculture Research System (CARS-01-75).

\section{REFERENCES}

Asman, W.A.H., Sutton, M.A., and Schorring, J.K. 1998. Ammonia emission, atmospheric transport and deposition. New Phytologist 139(1):27-48.

Cai, Y.X., Liu, C.X., Wang, W., and Cai, K.Z. 2011. Differences in physicochemical properties of kernels of two rice cultivars during grain formation. Journal of the Science of Food and Agriculture 91:1977-1983.

Dou, Z., Tang, S., Li, G.H., Liu, Z.H., Ding, C.Q., Chen, L., et al. 2017. Application of nitrogen fertilizer at heading stage improves rice quality under elevated temperature during grain-filling stage. Agronomy Journal 57(4):2183-2192.

Guetral, E.A. 2000. Preplant slow-release nitrogen fertilizers produce similar bell pepper yields as split applications of soluble fertilizer. Agronomy Journal 92(2):388-393.

Halvorson, A.D., Alluvione, F.D., and Grosso, S.J. 2010. Tillage and inorganic nitrogen source effects on nitrous oxide emissions from irrigated cropping systems. Soil Science Society of America Journal 74:436-445. 
Huang, X., Tang, S.H., Xu, P.Z., Chen, J.S., and Zhang, F.B. 2006. Effects of one-time application of controlled-release fertilizer on growth and grain yield in super rice cultivar. Guangdong Agricultural Sciences 9:16-19.

Huang, Q.Y., Tang, S.H., Zhang, F.B., Zhang, M., Huang, X., Huang, J.F., et al. 2017. Effect of combined application of controlled-release urea and conventional urea under reduced $\mathrm{N}$ rate on yield and $\mathrm{N}$ utilization efficiency of rice. Chinese Journal of Eco-Agriculture 25(6):829-838.

Jin, J.Y. 2012. Changes in the efficiency of fertilizer use in China. Journal of the Science of Food and Agriculture 92:1006-1009.

Jin, J.Y., and Yan, X. 2005. Changes of fertilizer use efficiency in China. In Plant Nutrition for Food Security, Hunan Health and Environmental Protection. p. 892-893. Tsinghua University Press, Beijing, P.R. China.

Kramer, A.W., Doane, T.A., Horwath, W.R., and Kessel, C.V. 2002. Combining fertilizer and inorganic inputs to synchronize N supply in alternative cropping systems in California. Agriculture Ecosystems Environment 91:233-243.

Li, S.T., He, P., and Jin, J.Y. 2013. Nitrogen use efficiency in grain production and the estimated nitrogen input/output balance in China agriculture. Journal of the Science of Food and Agriculture 93:1191-1197.

Liu, Q.H., Wu, X., Chen, B.C., Xin, C.Y., Chen, F., Wang, Y., et al. 2014. Effects of different irrigation methods on grain quality of japonica rice in Huanghuai District of China. Chinese Journal of Applied Ecology 25(9):2583-2590.

Liu, Q.H., Wu, X., Ma, J.Q., and Xin, C.Y. 2015. Effects of cultivars, transplanting patterns, environment, and their interactions on grain quality of japonica rice. Cereal Chemistry 92(3):284-292.

Lu, X.H., Wu, L.H., Pang, L.J., Li, Y.S., Wu, J.G., Shi, C.H., et al. 2007. Effects of plastic film mulching cultivation under nonflooded condition on rice quality. Journal of the Science of Food and Agriculture 87:334-339.

Martin, M., and Fitzgerald, M.A. 2002. Proteins in rice grains influence cooking properties! Journal of Cereal Science 36:285-294.

Meng, L., Zhang, X.L., Jiang, X.F., Huang, Q.W., Xu, Y.C., Yang, X.M., et al. 2009. Effects of partial mineral nitrogen substitution by organic fertilizer nitrogen on the yields of rice grains and its proper substitution rate. Journal of Plant Nutrition and Fertilizer 15(2):290-296.

Miao, X.K., Xing, X.M., Ding, Y.F., Liu, Z.H., Tang, S., Ding, C.Q., et al. 2016. Yield and nitrogen uptake of bowl-seedling machine-transplanted rice with slow-release nitrogen fertilizer. Agronomy Journal 108:313-320.

Ministry of Agriculture PR China. 1988. Method for rice quality measurement. p. 4-6. Standard of Ministry of Agriculture, P.R. China NY147-88. Chinese Standard Press, Beijing, P.R. China.

Moe, K., Mg, K.W., Win, K.K., and Yamakawa, T. 2017. Effects of combined application of inorganic fertilizer and organic manures on nitrogen use and recovery efficiencies of hybrid rice. American Journal of Plant Science 8:1043-1064.

Peng, Y., Ma, J., Jiang, M.J., Yan, F.J., Sun, Y.J., and Yang, Z.Y. 2013. Effects of slow/controlled release fertilizers on root morphological and physiological characteristics of rice. Journal of Plant Nutrition and Fertilizer 19(5):1048-1057.

Shoji, S., Delgado, J.A., Mosier, A., and Miura, Y. 2001. Use of controlled release fertilizers and nitrification inhibitors to increase nitrogen use efficiency and to conserve air and water quality. Communications in Soil Science and Plant Analysis 32:1051-1070.

Tang, X.G., Liu, G.R., Xu, C.X., Yuan, F.S., Qin, W.J., Wang, P., et al. 2015. Effect of organic-inorganic fertilizer application ratio on rice grain weight and seed-setting rate at different position of rice spike. Journal of Plant Nutrition and Fertilizer 21(5): 1336-1342.

Toyoshima, H., Okadome, H., Ohtsubo, K., Suto, M., Horisue, N., Instsu, O., et al. 1997. Cooperative test on the small-scale method for the gelatinization properties test of rice flours with a Rapid Visco Analyzer (RVA). Nippon Shokuhin Kagaku Kogaku Kaishhi 44:579-584.

Wang, Q.S., Huang, P.S., Zhen, R.H., Jing, L.M., Tang, H.B., and Zhang, C.Y. 2004. Effect of rice-duck mutualism on nutrition ecology of paddy field and rice quality. Chinese Journal of Applied Ecology 15(4):639-645.

Wang, Q.J., Zhang, L., Zhang, J.C., Shen, Q.R., Ran, W., and Huang, Q.W. 2012. Effects of compost on the chemical composition of SOM in density and aggregate fractions from rice-wheat cropping systems as shown by solid-state 13C-NMR spectroscopy. Journal of Plant Nutrition and Soil Science 175:920-930.

Wilson, M.L., Rosen, C.J., and Moncrief, J.F. 2010. Effects of polymer-coated urea on nitrate leaching and nitrogen uptake by potato. Journal of Environmental Quality 39:492-499.

Xing, X.M., Li, X.C., Ding, Y.F., Wang, S.H., Liu, Z.H., Tang, S., et al. 2015. Effects of types of controlled released nitrogen and fertilization modes on yield and dry mass production. Scientia Agriculture Sinica 48(24):4892-4902.

Zhang, H., Wang, M.C., Xu, G.H., and Yan, Z. 2014. Bio-organic fertilizers as the foundation of agricultural sustainable development: on the application of bio-organic fertilizers on rice cropping. Journal of Huaihai Institute Technology (Humanities and Social Science Edition) 12(6):94-96.

Zhang, H., Zhang, S.F., Yang, J.C., Zhang, J.H., and Wang, Z.Q. 2008. Postanthesis moderate wetting drying improves both quality and quantity of rice yield. Agronomy Journal 100(3):726-734.

Zhu, Z.L., and Li, J.K. 2003. Rational use of inorganic and organic fertilizers and development of environment friendly fertilizer system. Journal of Chinese Academy of Science 18:89-91. 